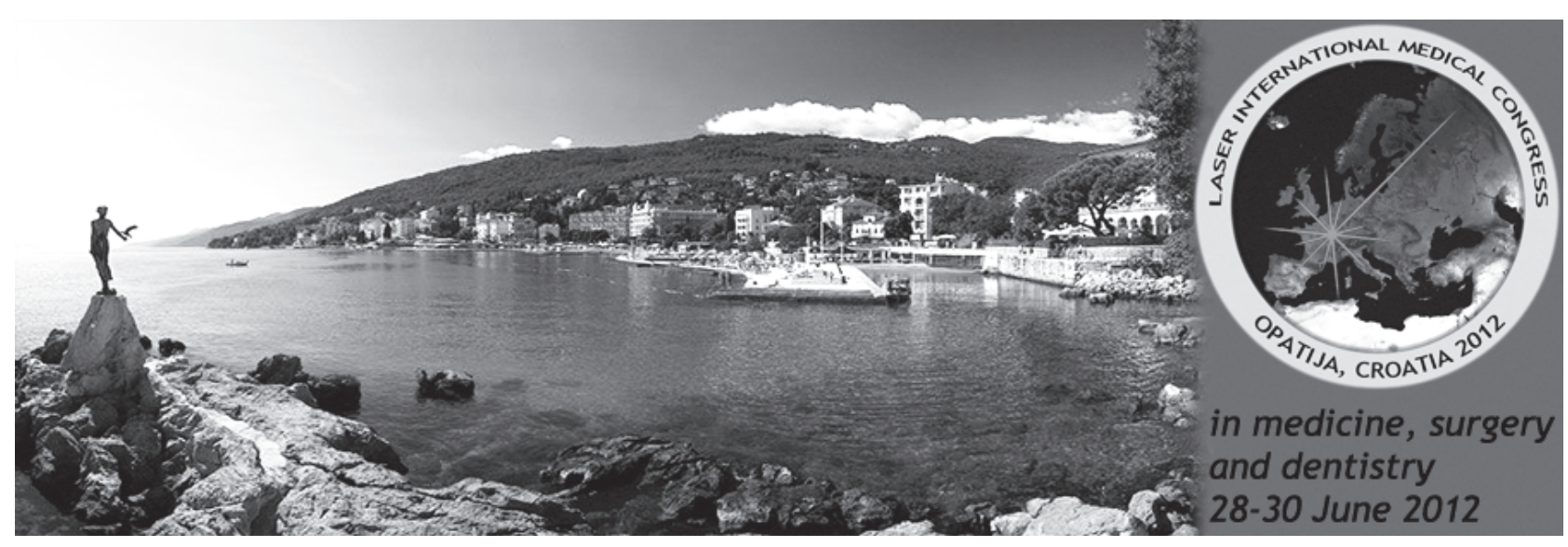

\title{
LASER INTERNATIONAL MEDICAL CONGRESS
}

\author{
with Celebration of EMLA 30th anniversary \\ Opatija- Croatia, June 27th-30th, 2012
}

\author{
FIRST ANNOUNCEMENT
}

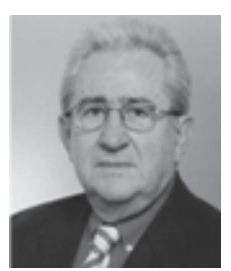

Dear collegues,

It is our great pleasure to invite you to Laser international medical congress 2012, that will take place in town Opatija, Croatia in Grand hotel Četiri opatijska cvijeta. The puprose of this congress is to show new researches and knowledges in field of laser application in medicine with analysis and recommendations for laser application in future.

Congress will bring together multidisciplinary laser experts from all over the world that are using thermal or surgical laser and athermal or low power lasers (LLLT) in basic science and clinical applications. We are certain that that congress programme will be interesting for all practitioners who use lasers in they everyday practice as well as for those who are considering to do so.

The laser medicine and technology are rapidly marching ahead. They are developing probably faster then any other segment of science, presenting new ways in medicine, surgery, dentistry and many other medical fields. As one of the pioneers in this field of medicine with clinical experience of more than 30 years, I cannot but ask: Quo vadis, laser or here are you going laser? Where are the limits of laser application in technology and medicine? The main purpose of our congress is to try to answer to these questions.

It our particular priviledge to host and organise 30th anniversary celebration of the European medical laser association (EMLA).

We hope that you will see that this congress is the great opportunity for you to improve your knowledge in professional sense, to exchange experiences with your international colleagues and also a chance to have very pleasant and interesting holiday in attractive town Opatija on the Adriatic coast town with beutiful nature, rich history and culture.

Hope to see you in Opatija,

Zlatko Simunovic, MD, FMH, ass.prof

Organisator and honorary president of EMLA 


\section{CONGRESS GENERAL INFORMATION:}

Date: 27-30th June 2012

Location: Opatija, Grand hotel Četiri Opatijska cvijeta

http://www.milenijhoteli.hr/mil/hr/hotelihr/milenij-grand-hotel-4-opatijska-cvijeta

Official language: english

\section{Main topics:}

- Basic science

- Thermal or surgical laser:

- Athermal or low power laser (LLLT)

- Dentistry thermal and athermal laser

- Workshops

- Exhibition

In: physics, biophysics, oncology, dermatology, laser acupuncture, rheumatology, neurology, photodynamic therapy, ENT, ophtalmology, surgery, dentistry, holistic medicine, laser safety, etc.

Congress scientific coordinators : Zlatko Simunovic, MD, FMH, ass.prof, Switzerland

Kresimir Simunovic, DDS, M.Sc., Laser klinik,Zurich, Switzerland

Dijana Kanjuh, univ.bacc.oec, Opatija, Croatia

Congress general secretary: Dijana Kanjuh, univ. bacc.oec, Opatija, Croatia

Assistant to secretary: Kristina Brlek, Opatija, Croatia

Eugen Brlek, Opatija, Croatia

Contact information: e-mail : info@lasermedico.ch

\section{Congress coordinators:}
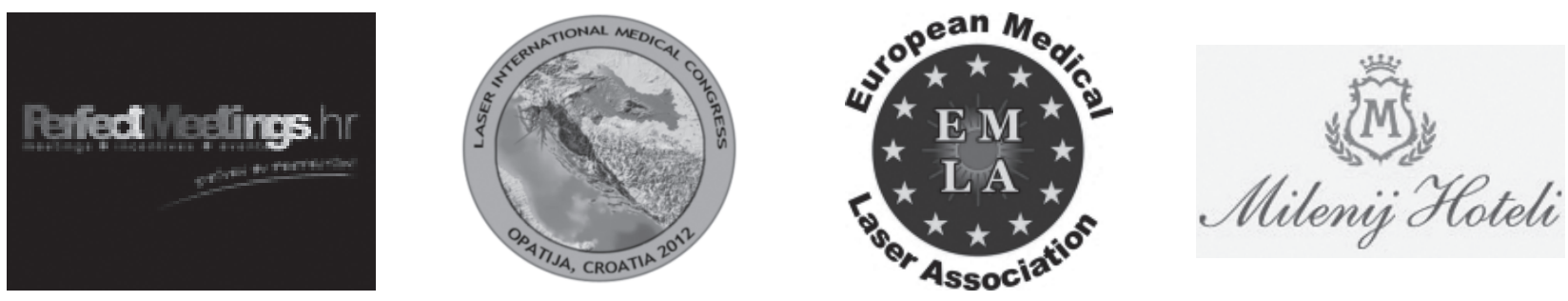